\title{
Thirst Trajectory and Factors Associated With Persistent Thirst in Patients With Heart Failure
}

\author{
Nana Waldréus, Martje H. L. van der Wal, Robert Hahn, Dirk J. van Veldhuisen and Tiny \\ Jaarsma
}

\section{Linköping University Post Print}

\section{Tweet}

N.B.: When citing this work, cite the original article.

Original Publication:

Nana Waldréus, Martje H. L. van der Wal, Robert Hahn, Dirk J. van Veldhuisen and Tiny Jaarsma, Thirst Trajectory and Factors Associated With Persistent Thirst in Patients With Heart Failure, 2014, Journal of Cardiac Failure, (20), 9, 689-695.

http://dx.doi.org/10.1016/j.cardfail.2014.06.352

Copyright: Elsevier http://www.elsevier.com/

Postprint available at: Linköping University Electronic Press http://urn.kb.se/resolve?urn=urn:nbn:se:liu:diva-111268 
Thirst trajectory and factors associated with persistent thirst in patients with heart failure

Nana Waldréus, RN, ${ }^{1,2}$ Martje H.L. van der Wal, RN, PhD, ${ }^{3}$ Robert G Hahn, MD, PhD, ${ }^{2,4}$ Dirk J van Veldhuisen, MD, PhD, ${ }^{3}$ Tiny Jaarsma, $\mathrm{RN}, \mathrm{PhD}^{1}$

Linköping and Södertälje, Sweden; and Groningen, The Netherlands

From the ${ }^{1}$ Department of Social and Welfare Studies, Faculty of Health Sciences, Linköping University, Linköping, Sweden; ${ }^{2}$ Department of Research, Södertälje Sjukhus, Södertälje, Sweden; ${ }^{3}$ Department of Cardiology, University of Groningen, University Medical Center Groningen, Groningen, The Netherlands; ${ }^{4}$ Department of Medicine and Health Sciences, Faculty of Health Sciences, Linköping University, Linköping, Sweden.

Reprint requests: Nana Waldréus, RN, Department of Social and Welfare Studies, Linköping University, Kungsgatan 38, 60174 Norrköping, Sweden. Tel: +46 76774 51 99; Fax: +46 8 5502 4375. E-mail: waldreus@tele2.se 


\begin{abstract}
Background: Thirst is often increased in patients with Heart Failure (HF) and can cause distress during the course of the condition. The aim of the present study was to describe the trajectory of thirst during an 18-month period and to identify variables associated with persistent thirst in patients with HF.

Methods and Results: Data were collected from 649 patients with HF with the use of the Revised Heart Failure Compliance Scale at 1, 6, 12 and 18 months after a period of hospital treatment for worsening HF. Thirst trajectory was described for the four follow-up visits and logistic regression analysis was used to identify factors independently associated with persistent thirst. In total, $33 \%(n=212)$ of the patients reported thirst on one or more occasions and $34 \%$ $(n=46)$ continued to have thirst at every follow-up visit. Nineteen percent $(n=121)$ of the patients had persistent thirst. Patients with persistent thirst were more often younger and male and had more HF symptoms. Higher body mass index and serum urea also increased the risk of persistent thirst.
\end{abstract}

Conclusions: Patients with HF who were thirsty at the 1-month follow-up were more often also thirsty at subsequent visits. Assessment of thirst is warranted in clinical practice because onefifth of patients suffer from persistent thirst.

Keywords: Thirst, heart failure, trajectory, persistent thirst 


\section{Introduction}

The prevalence of patients with heart failure (HF) in society is increasing owing to an aging population and improvement of cardiovascular treatment. From $10 \%$ to $20 \%$ of people aged 70 80 years are estimated to have HF. ${ }^{1}$ These patients experience a large number of symptoms, such as dyspnoea and fatigue, which affect their daily functioning and quality of life. ${ }^{1-4}$ Thirst is a well recognized but rarely studied symptom. In a recent review we showed that patients with HF have increased thirst, which causes distress. ${ }^{5}$ Thirst is a natural physiological function, which serves to maintain fluid balance. It can be defined as a desire for drinking water and develops into a strong desire to drink that is difficult to ignore. ${ }^{6}$

In patients with $\mathrm{HF}$, thirst intensity was graded as $23-75 \mathrm{~mm}$ on a visual analogue scale (100 $\mathrm{mm}$ ), and patients with worsening HF graded the thirst to be of relatively higher intensity. ${ }^{5,7}$ Forty-six percent of patients with HF described thirst as troublesome ${ }^{8}$ and could not find anything that helped to reduce their thirst for more than a short period of time. ${ }^{9}$

Persistent thirst can affect the patient's ability to manage daily activities, including self-care and adherence to fluid restriction. ${ }^{2,5,9}$ There is no knowledge of the thirst trajectory in HF or of the number of patients who suffer from persistent thirst. Persistent thirst has been described only in patients with HF during their last 6 months of life ${ }^{4}$ and is possibly related to factors associated with HF treatment, psychological factors, such as anxiety, and higher New York Heart Association (New York Heart Association) functional class. ${ }^{5}$

To increase the knowledge about thirst in patients with HF, the main objectives of the present study were to (i) examine the thirst trajectory and describe HF patients with persistent thirst during an 18-month period and (ii) determine factors associated with persistent thirst. Displaying changes over time helps us to understand how many patients with HF continuously experience thirst. Mapping the thirst trajectory is also a first step toward alerting health care professionals to the possibility of persistent thirst and the need for intervention.

\section{Methods}

For this study we used a descriptive, prospective design with data from the Coordinating Study Evaluating Outcomes of Advising and Counselling in Heart Failure (COACH) study. ${ }^{10}$ This was a randomised, controlled study with 1,023 HF patients that aimed to determine the effectiveness of two interventions with basic and intensive nurse-led HF care, compared to conventional care as presented elsewhere. ${ }^{10,11}$ Inclusion criteria for $\mathrm{COACH}$ were hospital 
admission for HF, evidence of structural underlying heart disease, and age $>18$ years. Exclusion criteria were participation in another study, inability to complete questionnaires and a recent or planned invasive cardiac intervention. The central Ethics Committee approved the study, and every patient provided written informed consent. The study complied with the Declaration of Helsinki.

Data collection for patients in the $\mathrm{COACH}$ study took place by an independent data collector on 5 occasions: at the index hospitalization (baseline) and at follow-up visits 1, 6, 12 and 18 months after discharge. The patients completed questionnaires about compliance with fluid restriction (all data collection time points) and depressive symptoms (baseline). Prescription of treatment, such as fluid and sodium restriction, was made by the physician at the clinic based on clinical judgement, current guidelines, and hospital protocol.

\section{Assessment of thirst}

To assess thirst at each follow-up visit, the subscale 'compliance with fluid restriction' from the Revised Heart Failure Compliance Scale was used. ${ }^{12}$ When patients reported problems complying with fluid restriction, they were asked "Why is it difficult to maintain fluid restriction?" Possible answers were: 'lack of self-motivation'; 'unable to control fluid restriction'; 'I did not know I had to restrict my fluid intake'; 'thirst'; or 'other'. When a patient reported thirst as being the reason for problems with fluid restriction, 1 point was assigned.

Data on thirst from baseline were not incorporated into the thirst trajectory, because worsening HF was regarded to be a confounder. ${ }^{7}$ For this sub-study, we included patients who completed the questionnaire on compliance with fluid restriction on at least 3 out of 4 followup occasions. When patients had 1 missing value regarding measurement of compliance with fluid restriction, this was substituted by the most frequently reported answer for having thirst (yes or no) on the 4 follow-up occasions. The total thirst score could theoretically range from 0 to 4 points (Fig. 1). In the analyses for this sub-study, 102 patients were excluded because they completed the fluid restriction compliance questionnaire $<3$ times. Another 272 patients died during the study period (Fig. 2) which led to high percentages (38 to 99) of nonavailable data from 1 to 18 months.

The description of the thirst trajectory, defined as the course of thirst, thus began at the 1month follow-up with the number of patients with or without thirst. The patients were then followed with the same questionnaire on each follow-up occasion up to 18 months after discharge. Persistent thirst was defined as having thirst $\geq 2$ times, and not having persistent thirst was defined as having thirst $\leq 1$ times during the study period (Fig. 1). 


\section{Additional data}

Clinical and demographic variables at baseline were retrieved from the patients' medical records. Depressive symptoms were assessed with the use of the Centre for Epidemiological Studies Depression Scale (CES-D). ${ }^{13}$ This 20-item self-report questionnaire measures the presence of depressive feelings and behaviours on a 4-point Likert scale ranging from 0 (rarely or none of the time) to 3 (most or all the time). The total sum score ranges from 0 to 60 points, with higher scores indicating higher presence of depressive symptoms. A score of $\geq 16$ points indicates presence of depressive symptoms. ${ }^{13}$

Presence of the following 10 symptoms was assessed by interviewing the HF patients: ankle oedema after waking up, ankle oedema during course of the day, difficulty sleeping, decreased appetite, fatigue, dyspnoea during rest, dyspnoea lying down, dyspnoea during exercise, cough, and dry cough. The total number of symptoms was obtained by summing all symptoms.

\section{Data analysis}

To examine the thirst trajectory, the occurrences of thirst (yes or no) were summarised in each follow-up examination (1, 6, 12, and 18 months). Descriptive statistics were used to describe the study population at baseline depending on the presence or absence of persistent thirst. Data is presented as mean $\pm \mathrm{SD}$, median (interquartile range [IQR]), or $\mathrm{n}(\%)$. The Cochran $Q$ test was used to compare the occurrences of thirst at each follow-up with the occurrence of thirst at 1 month after the hospital discharge for worsening HF. Univariate analyses were used to identify variables associated with persistent thirst. These included the independent $t$ test (continuous normally distributed), and the Mann-Whitney $U$ test (continuous skewed). Categoric variables were analysed with the use of chi-square tests. Variables showing a difference of $P<0.15$ were entered in a logistic regression analysis, which was performed with a backward method to identify which theoretically relevant factors were independently associated with persistent thirst. An odds ratio $>1$ indicates higher probability for persistent thirst, and an odds ratio $<1$ indicates lower probability for persistent thirst. A $P$ value of less than 0.05 was considered to be significant. Data were analyzed with the use of Statistical Package for Social Sciences (SPSS) version 20 (SPSS, Chicago, Illinois). 


\section{Results}

\section{Study population}

A total of 649 patients were included in this substudy. Mean age of the included patients was $69 \pm 12$ years, and $62 \%(n=404)$ were men. The mean left ventricular ejection fraction was $33 \% \pm 14 \%, 44 \%(n=282)$ were in NYHA functional class III-IV at discharge from hospital, and $95 \%(n=619)$ were prescribed diuretics (Table 1). Of the 1023 patients in COACH a total of 374 were not included in this substudy: 272 patients died, and 102 completed the fluid restriction compliance questionnaire $<3$ times. Excluded patients were slightly older (74 vs 69 years) and more often in NYHA functional class III-IV (57\% vs 44\%).

In total, $66 \%(\mathrm{n}=382)$ of the included patients were advised to restrict their fluid intake and $87 \%(n=564)$ to restrict their sodium intake (Table 1). Of the patients with persistent thirst $60 \%$ were prescribed $2000 \mathrm{mg}$ sodium/day and $40 \%$ were prescribed $3000 \mathrm{mg}$ sodium/day compared with $70 \%$ and $30 \%$, respectively, of patients without persistent thirst.

The prevalence of thirst at the 1-month follow-up was $21 \%(n=136)$, but decreased slightly for each follow-up during the study, ending with $17 \%(n=108)$ at 18 months. Of the 649 patients, $19 \%(\mathrm{n}=121)$ had persistent thirst, which was defined as having thirst at $\geq 2$ follow-up occasions (Fig. 1).

\section{Trajectory of thirst in heart failure}

Figure 3 shows the observed thirst trajectory depending on whether the patients reported thirst or not, starting with the first follow-up visit at 1 month and proceeding to the last follow-up visit at 18 months. At the 1-month follow-up, 136 (21\%) of all patients were thirsty, of which 46 (34\%) continued to report thirst during the rest of the follow-up, 44 (32\%) no longer reported thirst after the 1-month follow-up, and 46 (34\%) reported thirst on two or three of the followup occasions.

Out of the 513 (79\%) patients who did not report thirst at 1 month, $29(6 \%)$ had thirst on the following two or three occasions and 47 (9\%) had thirst on one occasion (Fig. 3).

Figure 4 shows the number of times on which the patients reported thirst. A total of $212(33 \%)$ patients reported thirst on at least one occasion. Of these patients, 91(43\%) reported thirst on one occasion and $121(57 \%)$ reported thirst on two to four occasions. Patients who reported thirst at 1 month were significantly more often thirsty also at 6,12 and 18 months (about 50\%) compared with those who did not report thirst at 1 month $(7-8 \%)(P<0.003)$ (Table 2). 


\section{Factors related to persistent thirst in heart failure}

A univariate analysis showed that patients with persistent thirst were significantly younger (64 vs 70 years old; $P<0.01$ ), and more often male (75\% vs 59\%; $P<0.01$ ) (Table 1). They also had a higher body mass index (BMI; $29 \pm 6 \mathrm{vs} 27 \pm 5 \mathrm{~kg} / \mathrm{m}^{2} ; P<0.01$ ). Patients with persistent thirst also had more HF symptoms ( $4 \pm 3$ vs $3 \pm 2 ; P<0.01$ ), and higher depression scores, with CES-D scores of 14.5 (interquartile range [IQR] 8-25) versus 12.0 (IQR 6-19; $<0.02)$.

There were no significant differences between patients with and without persistent thirst regarding prescribed fluid restriction $(62 \%$ vs $67 \% ; P=0.3)$ and sodium restriction $(88 \%$ vs $87 \% ; P=0.8)$ (Table 1).

In the multivariate logistic regression model, higher BMI (odds ratio [OR] 1.06; $P<0.01$ ), higher serum urea (OR 1.05; $P<0.05$ ), and more HF symptoms (OR 1.14; $P<0.05$ ) were independently associated with persistent thirst (Table 3). Older age (OR 0.96; $P<0.001)$ and being female (OR 0.43; $P<0.01)$ decreased the odds of having persistent thirst. There was a trend that the CES-D score was higher in those with persistent thirst (OR 1.04; $P=0.07)$.

\section{Discussion}

To our knowledge, this is the first study to examine thirst trajectory in patients with HF and factors associated with persistent thirst. The findings show that one-third of the patients who were thirsty at the 1-month follow-up continued to be thirsty at all follow-up time points. Whereas temporary thirst focuses on momentarily alleviating thirst by drinking, ${ }^{6}$ persistent thirst can be experienced as an ongoing and troublesome sensation. ${ }^{5}$ Based on our definition, $19 \%$ had persistent thirst, because they were thirsty at $\geq 2$ of 4 follow-up visits. This subgroup might require greater involvement by health care providers.

Patients with worsening of HF and patients with HF at the end of life are known to frequently suffer from persistent thirst. ${ }^{4,5}$ However, some patients with HF apparently remain in this troublesome situation for a much longer period of time during stable parts of their chronic condition, or at least for 18 months as shown in the present study. Patients who were once thirsty were still more likely to once again become thirsty, which indicates the importance of assessment of thirst. Our analysis shows that the likelihood of thirst over time is greatly dependent on whether thirst was reported or not at 1 month. As presented in Table 2, the majority of those who were not thirsty at one month did not report thirst on later occasions. 
Although the proportion of thirst seems to be stable over time, there were also new-onset cases. Nevertheless, for many of the patients, thirst came and went during the 18-month study period. The finding of temporary thirst is consistent with other symptom trajectories in HF, including depressive symptoms or sexual problems, which shows that symptoms often disappear spontaneously or at least without clear medical intervention. ${ }^{14,15}$ Other patients develop new symptoms ${ }^{14,15}$ that cause distress, trigger hospitalization, and increase mortality. ${ }^{14,16}$

In the present study, patients with persistent thirst were significantly younger than those without persistent thirst. Studies have shown that thirst becomes blunted with age. Reduced cerebral blood flow and attenuated sensitivity of receptors responding to changes in central blood flow serve to explain thirst impairment in the elderly. ${ }^{17,18}$ Men with HF were also more prone to have persistent thirst. Studies on healthy persons show that men are usually slightly dehydrated, which can initiate increased thirst. ${ }^{19}$

The number of symptoms experienced in patients with HF can be as many as $15 .^{3}$ Dyspnea, lack of energy and dry mouth are the most prevalent ones. We found that the number of HF symptoms was associated with persistent thirst. It is previously known that increased symptom prevalence in HF has a negative impact on well-being and quality of life. ${ }^{3}$

High serum urea was one of the factors related to persistent thirst. Serum urea might be a guide to patient hydration status, but can also serve as a surrogate for neurohormonal activation. $^{20,21}$ Angiotensin II, which initiates drinking, is a vasoactive hormone and a part of the well known hormonal activation cascade. ${ }^{6,22}$ Finally, BMI was associated with persistent thirst. One explanation of this finding could be that the prescribed fluid restriction was the same regardless of body weight. Fluid restriction is generally prescribed as a specific volume of fluids and not adjusted to physiologic needs, which vary with body mass. ${ }^{2,6}$

Earlier studies described that troublesome thirst is promoted by fluid restriction in patients with $\mathrm{HF}^{5,9}$ but this association was not found in the present study. However, the prescribed fluid restriction is not necessarily the same as the amount of fluids consumed. Two randomized studies showed no differences in perceived thirst between HF patients with fluid restriction versus normal fluid intake. ${ }^{23,24}$ In contrast, two other studies found a significant decrease in thirst intensity with liberal fluid intake compared with fluid restriction. ${ }^{25,26}$ Evidently, thirst can be reduced by fluid intake that is adjusted according to body mass. In healthy volunteers, sympathetic arousal from physiologic strain, eg. tachycardia, was another factor that stimulates thirst. ${ }^{27}$ However, the importance of this mechanism is unclear in patients with HF.

A regular follow-up of the thirst trajectory may help health care professionals to display changes in thirst over time and to identify patients with troublesome thirst. Assessing thirst in 
patients with HF regularly, not only once, in hospital care as well as outpatient settings can be a key strategy to identify those who develop or have persistent thirst. Introducing a routine screening of thirst in treatment programs and clinical practice would be helpful in order to address troublesome thirst in patients with HF. Identification of signs and symptoms of worsening HF and or assessment of the effects of individual treatment such as diuretic therapy (too much or too little, etc) certainly plays a vital role in the ongoing and continuous care and maintenance of the outpatient HF patient.

Further research is needed to achieve a broader understanding of the thirst trajectory. The present findings should be confirmed by assessment directed at the presence of thirst in the daily life of patients with HF. It could provide an insight into HF as a syndrome, and information about thirst is necessary also to improve quality of life in many patients with HF.

\section{Study limitations and strengths}

One limitation is that the data collection was originally intended to answer other research questions. The assessment of thirst was based on self-reported answers on thirst in a questionnaire about compliance with fluid restriction, and this might have caused underreporting. Finally, since there is no official definition on persistent thirst, we used an arbitrary cutoff score to differentiate between patients with and without persistent thirst.

Nevertheless, the strengths of this study were the repeated assessments of thirst over a period of 18 months in a large sample of patients with HF. The prospective design examined the thirst trajectory and persistent thirst, which has not been done previously.

\section{Conclusions}

One third of patients with HF had thirst on one out of four regularly timed follow-up occasions during an 18-month study period. The patients who were thirsty at the 1-month follow-up visit were more often thirsty at subsequent examinations up to 18 months later. These findings suggest a need for assessing thirst to recognize and detect an incipient problem for patients with HF. The results may also be a guide to identify patients with a potential risk for persistent thirst, such as patients with a higher number of HF symptoms, higher BMI or serum urea and male sex.

\section{Disclosures}

None. 


\section{References}

1. McMurray JJ, Adamopoulus S, Anker SD, Auricchio A, Böhm M, Dickstein K, et al. ESC guidelines for the diagnosis and treatment of acute and chronic heart failure 2012: the Task Force for the diagnosis and treatment of acute and chronic heart failure 2012 of the European Society of Cardiology. Developed in collaboration with the Heart Failure Association of the ESC (HFA) and endorsed by the European Society of Intensive Care Medicine (ESICM). Eur J Heart Fail 2012;14:803-869.

2. Lainscak M, Blue L, Clark AL, Dahlström U, Dickstein K, Ekman I et al. Self-care management of heart failure: practical recommendations from the Patients Care Committee of the Heart Failure Association of the European Society of Cardiology. Eur J Cardiovasc Nurs 2011;13:115-126.

3. Zambroski $\mathrm{CH}$, Moser DK, Bhat G, Ziegler C. Impact of symptom prevalence and symptom burden on quality of life in patients with heart failure. Eur J Cardiovasc Nurs 2005;4:198-206.

4. Nordgren L, Sörensen S. Symptoms experienced in the last six months of life in patients with end-stage heart failure. Eur J Cardiovasc Nurs 2003;2:213-217.

5. Waldréus N, Hahn R, Jaarsma T. Thirst in heart failure: a systematic literature review. Eur J Heart Fail 2013;15:141-149.

6. Thornton S. Thirst and hydration: Physiology and consequences of dysfunction. Physiology and Behavior 2010;100:15-21.

7. Waldreus N, Sjöstrand F, Hahn RG. Thirst in the elderly with and without heart failure. Arch Gerontol Geriatr 2011;53:174-178.

8. Reilly CM, Meadows K, Dunbar S. Thirst and QOL in persons with heart failure. Heart Lung 2010;4:353.

9. Brännström M, Ekman I, Norberg A, Boman K, Strandberg G. Living with severe chronic heart failure in palliative advanced home care. Eur J Cardiovacs Nurs 2006;5:295-302. 
10. Jaarsma T, van Der Wal MH, Hogenhuis J, Lesman I, Luttik ML, Veeger NJ, van Veldhuisen DJ. Design and methodology of the COACH study: a multicenter randomised coordinat- ing study evaluating outcomes of advising and counselling in heart failure. Eur J Heart Fail 2004;6:227-33.

11. Jaarsma T, van der Wal M, Lesman-Leegte I, Luttik M-L, Hogenhuis J, Veeger NJ, Sanderman R, Hoes AW, van Gilst WH, Lok DJA, Dunselman PHJM, Tijssen JGP, Hillege HL, van Veldhuisen DJ. Effect of moderate or intensive disease management program on outcome in patients with heart failure. Arch Intern Med 2008;168:316-324.

12. Evangelista LS, Berg J, Dracup K. Relationship between psychosocial variables and compliance in patients with heart failure. Heart Lung 2001;30:294 -301.

13. Radloff L. A self-report depression scale for research in the general population. Appl Psychol Meas 1977;1:385-401.

14. Johansson P, Lesman-Leegte I, Lundgren J, Hillege HL, Hoes A, Sanderman R, van Veldhuisen DJ, Jaarsma T. Time-course of depressive symptoms in patients with heart failure. J Psychosom Res 2013;74:238-243.

15. Hoekstra T, Jaarsma T, Sanderman R, van Veldhuisen DJ, Lesman-Leegte I. Perceived sexual difficulties and associated factors in patients with heart failure. Am Heart $\mathrm{J}$ 2012;163:246-251.

16. Smith ORF, Kupper N, de Jonge P, Denollet J. Distinct trajectories of fatigue in chronic heart failure and their association with prognosis. Eur J Heart Fail 2010;12:841-848.

17. Farrell MJ, Zamarripa F, Shade R, Phillips PA, McKinley M, Fox PT, et al. Effect of aging on regional cerebral blood flow responses associated with osmotic thirst and its satiation by water drinking: a PET study. Proc Natl Acad Sci USA 2008; 105:382-387.

18. Stachenfeld NS, DiPietro L, Nadel ER, Mack GW. Mechanism of attenuated thirst in aging: role of central volume receptors. Am J Physiol 1997;272:R148-R157.

19. Hahn RG, Waldréus N. An aggregate urine analysis tool to detect acute dehydration. Int J Sport Nutr Exerc Metab 2013;23:303-311.

20. Kazory A. Emergence of blood urea nitrogen as a biomarker of neurohormonal activation in heart failure. Am J Cardiol 2010;106:694-700.

21. Gotsman I, Zwas D, Planer D, Admon D, Lotan C, Keren A. The significance of serum urea and renal function in patients with heart failure. Medicine 2010;89:197-203.

22. Sayer G, Bhat G. The renin-angiotensin-aldosterone system and heart failure. Cardiol Clin 2013;32:21-32.

23. Albert NM, Nutter B, Forney J, Slifcak E, Wilson Tang WH. A randomized controlled 
pilot study of outcomes of strict allowance of fluid rherapy in hyponatremic heart failure (SALT-HF). J Card Fail 2013;19:19:1-9.

24. Philipson H, Ekman I, Swedberg K. A pilot study of salt and water restrictiction in patients with chronic heart failure. Scand Cardiovasc J 2010;44:209-214.

25. Holst M, Strömberg A, Lindholm M, Uden G, Willenheimer R. Liberal versus restricted fluid prescription in stabilised patients with chronic heart failure: result of randomised cross-over study of the effects on health-related quality of life, physical capacity, thirst and morbidity. Scand Cardiovasc J 2008;42:316-322.

26. Aliti GB, Rabelo ER, Clausell N, Rohde LE, Biolo A, Beck-da-Silva L. Aggressive fluid and sodium restriction in acute decompensated heart failure. A randomized clinical trial. JAMA Intern Med 2013;173:1058-106.

27. Waldréus N, Hahn RG, Engvall J, Skoog J, Ewerman L, Lindenberger M. Thirst response to acute hypovolemia in healthy women and women prone to vasovagal syncope. Physiol \& Behavior 2013;120: 34-39. 


\section{Tables}

Table 1. Characteristics of the study patients, with and without persistent thirst

\begin{tabular}{|c|c|c|c|c|}
\hline \multirow{2}{*}{ Variable } & \multirow{2}{*}{$\begin{array}{c}\text { All patients } \\
(\mathrm{n}=649)\end{array}$} & \multicolumn{2}{|c|}{ Persistent Thirst } & \multirow[t]{2}{*}{$P$-value } \\
\hline & & $\begin{array}{c}\text { Yes }^{\mathrm{a}} \\
(\mathrm{n}=121)\end{array}$ & $\begin{array}{c}\mathrm{No}^{\mathrm{b}} \\
(\mathrm{n}=528)\end{array}$ & \\
\hline \multicolumn{5}{|l|}{ Demographics } \\
\hline Age, years & $69 \pm 12$ & $64 \pm 12$ & $70 \pm 11$ & $<0.01$ \\
\hline Men, $\%$ & 62 & 75 & 59 & $<0.01$ \\
\hline Cohabiting, $\%$ & 62 & 68 & 61 & 0.14 \\
\hline \multicolumn{5}{|l|}{ Clinical characteristics } \\
\hline NYHA class III-IV, \% & 44 & 45 & 44 & 0.87 \\
\hline Left ventricular ejection fraction, $\%$ & $33 \pm 14$ & $33 \pm 14$ & $33 \pm 14$ & 0.74 \\
\hline Duration of HF, days & $50(19-1058)$ & $98(21-1331)$ & $44(18-964)$ & 0.22 \\
\hline BMI, $\mathrm{kg} / \mathrm{m}^{2}$ & $27 \pm 5$ & $29 \pm 6$ & $27 \pm 5$ & $<0.01$ \\
\hline Systolic blood pressure, $\mathrm{mmHg}$ & $119 \pm 21$ & $119 \pm 22$ & $119 \pm 21$ & 0.87 \\
\hline Diastolic blood pressure, $\mathrm{mmHg}$ & $69 \pm 12$ & $71 \pm 12$ & $69 \pm 11$ & 0.06 \\
\hline Sodium, $\mathrm{mmol} / \mathrm{L}$ & $139 \pm 4$ & $139 \pm 4$ & $139 \pm 4$ & 0.44 \\
\hline Urea, mmol/L & $12 \pm 6$ & $12 \pm 6$ & $11 \pm 5$ & 0.11 \\
\hline Creatinine, umol/L & $117 \pm 44$ & $121 \pm 38$ & $116 \pm 45$ & 0.29 \\
\hline NT-proBNP, pmol/L & $2165(1115-4286)$ & $2073(992-4456)$ & $2171(1129-4252)$ & 0.63 \\
\hline \multicolumn{5}{|l|}{ Comorbidities, \% } \\
\hline Type II diabetes & 15 & 14 & 15 & 0.88 \\
\hline Type I diabetes & 10 & 10 & 10 & 0.88 \\
\hline Hypertension & 41 & 41 & 42 & 0.97 \\
\hline \multicolumn{5}{|l|}{ Medication, \% } \\
\hline ACE-inhibitors & 76 & 77 & 76 & 0.90 \\
\hline Angiotensin receptor blockers & 12 & 12 & 13 & 0.78 \\
\hline Calcium channel blockers & 15 & 17 & 15 & 0.66 \\
\hline Diuretics & 95 & 99 & 95 & 0.03 \\
\hline Antidepressive & 6 & 10 & 6 & 0.07 \\
\hline Aldosterone antagonist & 54 & 62 & 53 & 0.06 \\
\hline \multicolumn{5}{|l|}{ Fluid- and sodium restriction, \% } \\
\hline Fluid $\quad 1200-1800 \mathrm{ml} /$ day & 66 & 62 & 67 & 0.33 \\
\hline Sodium $2000-3000 \mathrm{mg}$ /day & 87 & 88 & 87 & 0.84 \\
\hline \multicolumn{5}{|l|}{ Depressive symptoms } \\
\hline Total scores & $12.0(7-20)$ & $14.5(8-25)$ & $12.0(6-19)$ & 0.02 \\
\hline Depressive symptoms, \% & 38 & 44 & 37 & 0.15 \\
\hline \multicolumn{5}{|l|}{ HF symptoms } \\
\hline Number of HF symptoms at 1 month & $3 \pm 2$ & $4 \pm 3$ & $3 \pm 2$ & $<0.01$ \\
\hline
\end{tabular}

Data is presented as mean $\pm \mathrm{SD}$, median $\left(25^{\text {th }}\right.$ and $75^{\text {th }}$ percentiles $)$, or as frequency.

HF: heart failure; NYHA: New York Heart Association; BMI: body mass index

${ }^{\text {a }}$ Patients reporting thirst $\geq 2$ times out of 4 follow-up visits.

${ }^{\mathrm{b}}$ Patients reporting thirst $\leq 1$ time out of 4 follow-up visits. 
Table 2. The proportion of patients with heart failure who were thirsty during the follow-up depending on whether thirst was present or not at 1 month

\begin{tabular}{lccc}
\hline 1 month N (\%) & 6 months N (\%) & 12 months N (\%) & 18 months N (\%) \\
\hline Not thirsty $(\mathrm{n}=513)$ & $40(7.8)$ & $18+21(7.6)$ & $11+3+8+15(7.2)$ \\
& & & \\
Thirsty $(\mathrm{n}=136)$ & $75(55.1)$ & $57+8(47.8)$ & $46+12+4+9(52.2)$ \\
\hline
\end{tabular}

Table 3. Logistic regression with factors associated with persistent thirst

\begin{tabular}{lcccc}
\hline & Odds Ratio & $95 \%$ Cl for Odds Ratio & $P$ value \\
Variable & & Lower & Upper & \\
\hline Age, years & 0.96 & 0.94 & 0.98 & $<.001$ \\
Gender, female & 0.43 & 0.23 & 0.74 & $<0.01$ \\
BMI, kg/m & 1.06 & 1.02 & 1.12 & $<0.01$ \\
Serum Urea, mmol/1 & 1.05 & 1.01 & 1.10 & $<0.05$ \\
Heart failure symptoms, number & 1.14 & 1.01 & 1.26 & $<0.05$ \\
Depressive symptoms, score & 1.04 & 1.00 & 1.05 & 0.07 \\
Diuretics & 5.21 & 0.65 & 41.7 & 0.12 \\
Antidepressive medication & 1.72 & 0.66 & 4.44 & 0.26 \\
Depressive symptoms & 0.74 & 0.31 & 1.77 & 0.50 \\
Co-habiting & 1.21 & 0.68 & 2.15 & 0.51 \\
Aldosterone antagonist & 1.09 & 0.65 & 1.84 & 0.75 \\
Diastolic blood pressure, $\mathrm{mmHg}$ & 1.00 & 0.68 & 2.15 & 0.82 \\
\hline
\end{tabular}

Model: $R^{2}=0.19$ (Nagelkerke); CI, confidence interval; BMI, body mass index. 


\section{Figures}

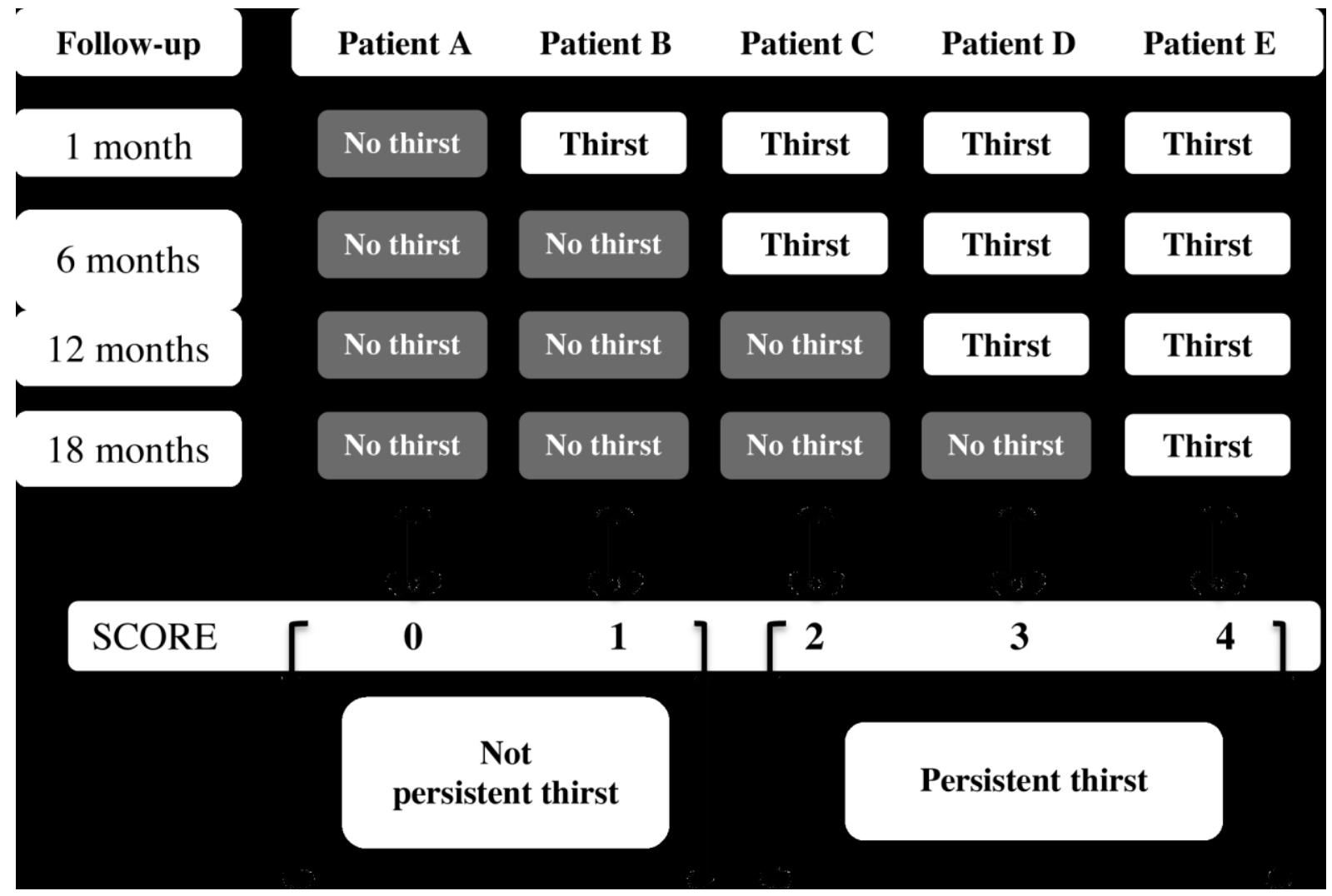

Fig. 1. Scoring for reported thirst at four follow-up visits over 18 months. Not persistent thirst is scored $0-1$, and persistent thirst is scored 2-4. 


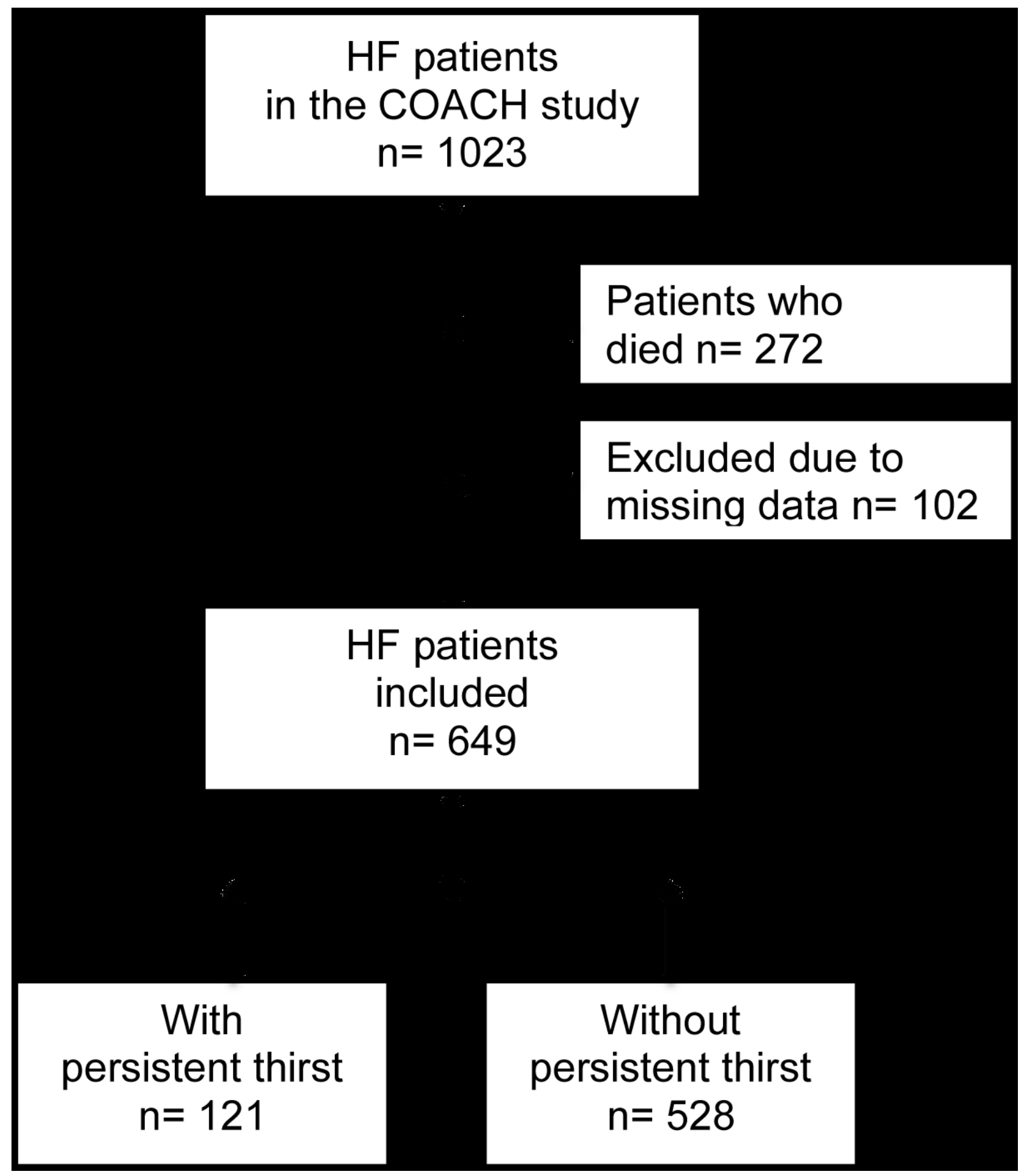

Fig. 2. Flowchart of patient inclusion. Patients were divided into groups with and without persistent thirst. HF, heart failure. 


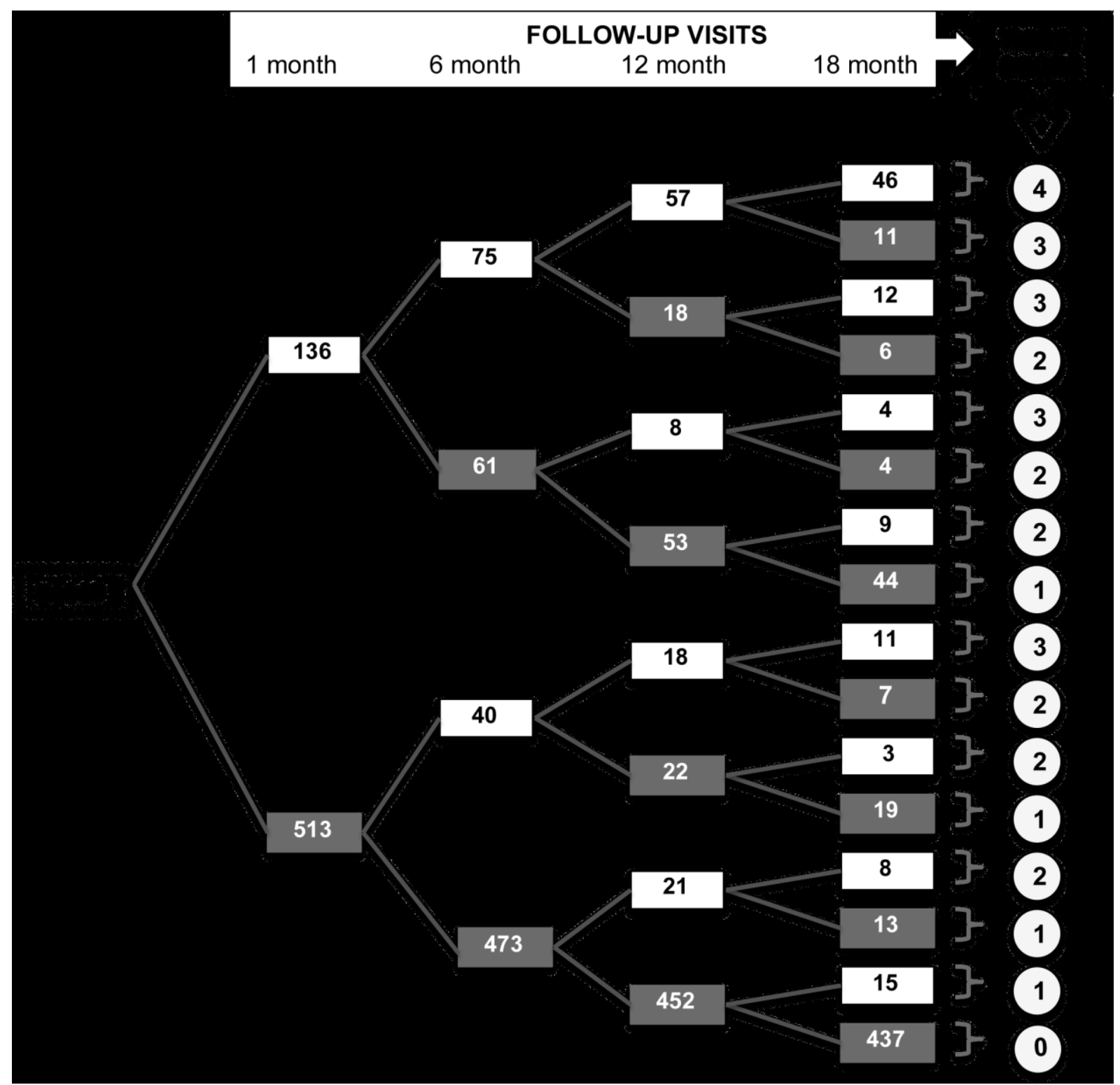

Fig. 3. The observed thirst trajectory presented with the number of heart failure patients with (white boxes) and without (grey boxes) thirst at each follow-up visit, and the summed number of times patients reported thirst (thirst score). 


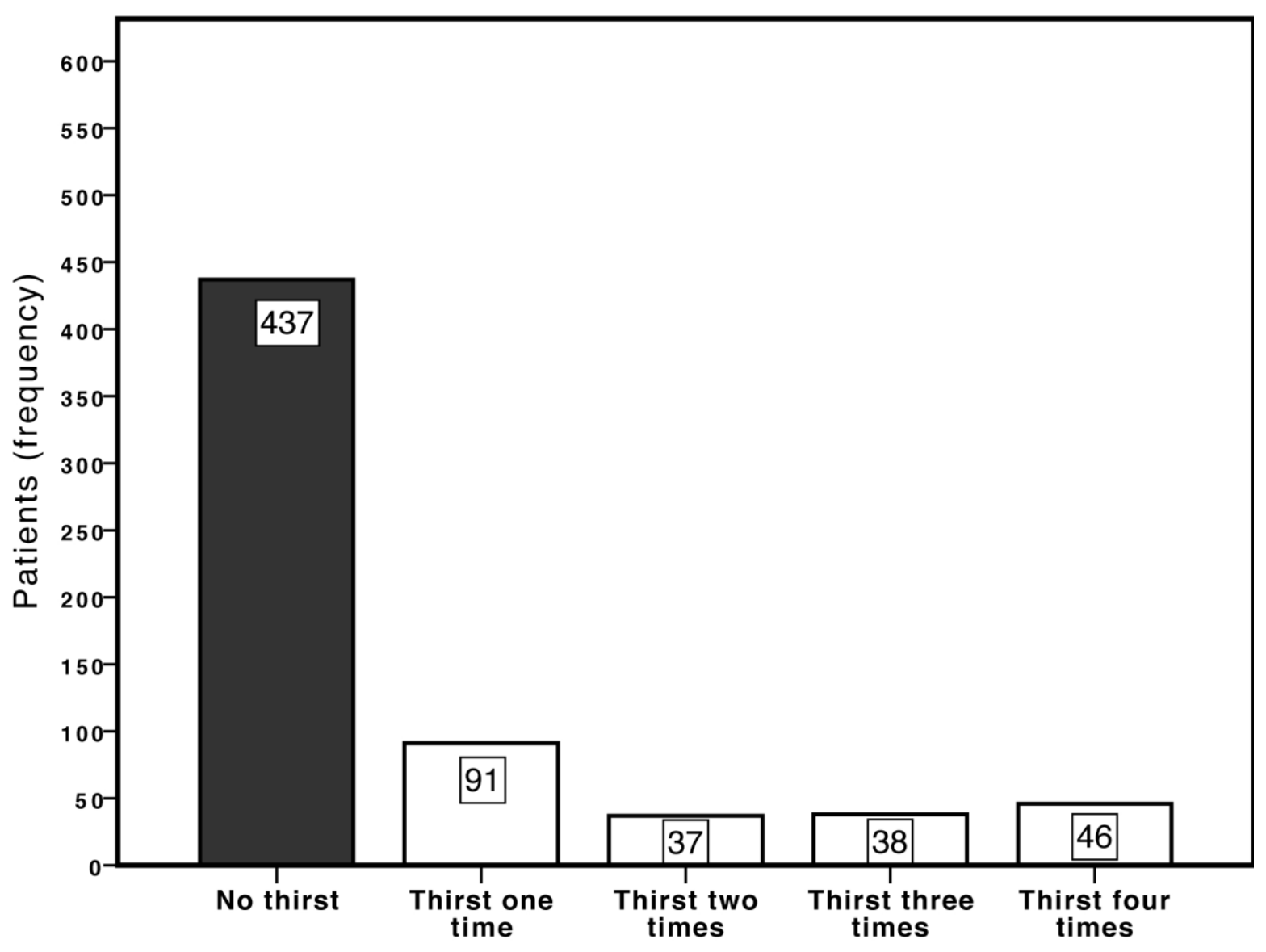

Fig. 4. Number of times thirst was reported during the 18-month follow-up. 